Magnetic and Electrical Separation, Vol. 9, pp. 260-261 Reprints available directly from the publisher Photocopying permitted by license only
(C) 1999 OPA (Overseas Publishers Association) N.V.

Published by license under the Gordon and Breach Science Publishers imprint. Printed in Malaysia.

\title{
EQUIPMENT AND PRODUCTS
}

\section{MEASURING SYSTEMS AND PUBLICATIONS FROM MAGNET-PHYSIK}

The Cologne-based company Magnet-Physik Dr. Steingroever GmbH has introduced several innovative magnetic measuring systems. Permagraph C-300 is suitable for the recording and analysis of hysteresis curves of permanent magnets. Remagraph C-500 is a measuring station for the investigation of static properties of soft magnetic materials. It is equipped with Permagraph C-300 with two electronic fluxmeters. Remacomp is a measuring system for the investigation of dynamic behaviour of soft magnetic materials. It can be employed for testing of not only amorphous strips with cross-section of $0.001 \mathrm{~cm}, \mathrm{c}$-cores and toroidal tape cores, but also complex geometries (rotor blades) and of steel samples (plates and sheets). Magnet-Physik also published three manuals devoted to magnetic measurement techniques, magnetisation and calibration of permanent magnet systems. Further information can be obtained on http://www.magnet-physik.de.

\section{A RECORD DIPOLE MAGNET}

In March 1997, a 1-metre niobium-tin dipole magnet, designed and built at Berkeley, reached a new record field of $13.3 \mathrm{~T}$, not long thereafter it reached $13.5 \mathrm{~T}$ at $1.8 \mathrm{~K}$. These values surpass the record set in 1995 of $11.03 \mathrm{~T}$ for a similar type of $50 \mathrm{~mm}$ bore, $1 \mathrm{~m}$ long model dipole that was built by Twente University in the Netherlands and tested at CERN.

\section{A NEW RARE-EARTH TUBE MAGNET}

Eriez Magnetics introduced their new rare-earth tube magnet. It is claimed that the new separator improves separation of fine and weakly 
magnetic impurities from pharmaceutical and chemical powders and in food processing. The new tube separator can be installed into existing grates and traps as it has the same dimensions as earlier models.

\section{RARE EARTH ROLL SEPARATORS FROM READINGS}

Readings of Lismore (Australia) have diversified by introducing a new rare earth roll separator. The most important innovation is claimed to be a correct feed presentation. This is achieved by introducing the inclined belt arrangement. The belt enables material to settle more quickly prior to separation and also the impact on the belt surface is lessened due to the decrease in the angle of impingement. This is claimed to lead to an extended belt life.

\section{A NEW MAGNETIC TRAP FROM ERIEZ}

Eriez Magnetics have developed a new ceramic magnet trap which is designed to remove both fine and coarse iron from glazes. The trap incorporates five or more of rare earth magnetic tubes. The tubes are claimed to be suitable for versatile installations, e.g. at a slip line, prior to spray drying or glaze spraying, or within glaze recycling lines.

\section{S/C MAGNET WHICH DOES NOT REQUIRE LH}

Japan Magnet Technology Co. Ltd. have in co-operation with Kobe Steel Co. Ltd. developed a mechanical refrigerator which can generate $5 \mathrm{~T}$ magnetic field in a bore $30 \mathrm{~cm}$ in diameter. The refrigerator was delivered to the University of Tokyo.

\section{PERMANENT ROLL SEPARATORS FOR DIAMOND RECOVERY}

Permanent magnetic roll separators supplied by Inprosys (USA) will be used to remove weakly magnetic material from alluvial gravel ahead of the gravity separation stage by Juina Mining Corp. This company will soon begin recovering diamonds in the Juina district of Mato Grosso in Brazil. 